Article

\title{
The Effect of the Precursor Solution's Pretreatment on the Properties and Microstructure of the SCS Final Nanomaterials
}

\author{
Olga Thoda ${ }^{1,2}$, Galina Xanthopoulou ${ }^{1,3}$, George Vekinis ${ }^{1}$ and Alexander Chroneos ${ }^{2, *} *$ \\ 1 Institute of Nanoscience and Nanotechnology, NCSR “Demokritos”, Agia Paraskevi Attikis, Athens 15310, \\ Greece; o.thoda@inn.demokritos.gr (O.T.); g.xanthopoulou@inn.demokritos.gr (G.X.); \\ g.vekinis@inn.demokritos.gr (G.V.) \\ 2 Faculty of Engineering, Environment and Computing, Coventry University, Priory Street, \\ Coventry CV1 5FB, UK \\ 3 Laboratory of Catalytic Processes in Gas Turbines, Samara State Aerospace University, \\ Moskovskoye Hwy 34, Samara 443086, Russia \\ * Correspondence: alexander.chroneos@imperial.ac.uk
}

Received: 25 January 2019; Accepted: 16 March 2019; Published: 21 March 2019

\begin{abstract}
Nanostructured nickel-based catalysts were produced by solution combustion synthesis and it was found that their properties and structure depended on the pretreatment of the precursor solution. X-ray diffraction, $\mathrm{N}_{2}$ adsorption, and an infrared high-speed camera were used to follow the various synthesis steps and to characterize the obtained catalysts, while their catalytic activity was determined in the hydrogenation of maleic acid. It was determined that the amount of water used and the heating of the precursor solution under mild stirring up to $70{ }^{\circ} \mathrm{C}$ influenced the nickel nitrate-glycine-water complexes that were formed in the precursor solution in the form of dendrites. These play a key role in the solution combustion synthesis (SCS) reaction mechanism and in particular in the formation of nickel-based catalysts. Understanding the interrelationships between the processing parameters and the ensuing powder properties allowed an efficient optimization of the catalytic performance.
\end{abstract}

Keywords: solution combustion synthesis; pretreatment; X-ray diffraction; surface analysis; infrared high-speed camera; nickel catalysts; nickel-based nanopowders

\section{Introduction}

The importance of acquiring deep knowledge and understanding of the mechanisms involved in a synthesis procedure is crucial in order to improve its efficiency. In this sense, the processing parameters and their effect on the final products play a key role. For a catalytic material, the knowledge that is essential for an efficient production is associated to the relation between the synthesis parameters, structure, morphology, microstructure, redox behavior, surface properties, and catalytic performance [1]. The high complexity of these relations highlights the necessity of systematic research on the synthesis process [2].

In terms of efficiency, not all solution-based approaches are equivalent. Each preparation methodology, including the solution routes such as solution combustion synthesis, the co-precipitation process, the sol-gel method, the hydrothermal technique, and the Pechini-like route, has its own advantages and disadvantages [3-7]. Most of them include costly reactants and in many cases intermediates are involved, which are moisture-sensitive [1]. As expected, all approaches are suitable to prepare some materials or to provide certain properties to the final products, while they are completely inappropriate for others. 
Solution combustion synthesis (SCS) is categorized as a soft-chemical method, and is a simple and cost-efficient approach yielding fine powders [8,9]. It involves the self-sustained redox reaction of an oxidant with a fuel in the presence of metal cations $[10,11]$. Generally, the oxidants are metal precursors (e.g., metal nitrates), and the fuel is any organic compound (e.g., urea, glycine, and citric acid) that is capable of forming complexes with metal ions [12]. The released heat from the exothermic reaction between the oxidants and the fuel fulfills the energy requirements for the formation of the final compounds [13]. The most significant advantage of the SCS method is its time and energy efficiency. Once the mixture reaches the necessary temperature, it ignites and the high self-generated energy converts the precursors into oxides and other compounds without demanding an external energy source. Conversely, other approaches based on metal hydroxide and/or alkoxide conversion are endothermic and thus require continuous external energy input [14].

There are many parameters that influence the properties of the produced materials, such as the preheating temperature, the initial composition, the fuel nature, the fuel concentration, etc. [15-17]. One of the parameters that have been considered to have low or no effect on the composition of the SCS-derived products is the quantity of water added in the initial solution. Xanthopoulou et al. [18] conducted a thorough investigation concerning this parameter, and it was concluded that the quantity of water in the precursor SCS solution does affect the composition and the microstructure of the final nanopowders. As a continuation of that work, in this research we demonstrate the influence of pretreatment of the precursor solution, performing heating on a plate up to $70{ }^{\circ} \mathrm{C}$ with mild magnetic stirring.

\section{Materials and Methods}

For a total solid mass of $14 \mathrm{~g}, 66.7 \%$ of nickel nitrate hexahydrate and $50 \%$ glycine were mixed with various quantities of water $(25,50,75,100 \mathrm{~mL})$ and eight solutions were prepared-two for each quantity of water. One solution from each water quantity was preheated in a borosilicate glass beaker on a hot plate with mild magnetic stirring until the temperature reached $70^{\circ} \mathrm{C}$. At that point, the beaker was placed in a preheated furnace at $500{ }^{\circ} \mathrm{C}$ in air atmosphere for the SCS to take place. The other four solutions (with $25,50,75$, and $100 \mathrm{~mL}$ of water) were placed directly in the furnace without any pretreatment. In all experiments, after the completion of the SCS cascade of reactions, the beaker was removed from the furnace and left to cool down to room temperature. In Table 1 that follows, the materials that have been used for catalysts production using Solution Combustion Synthesis (SCS) are listed. Also, the manufacturers and their assay are included.

Table 1. Materials used for SCS catalysts production and the hydrogenation reaction.

\begin{tabular}{ccc}
\hline Material & Manufacturer & Assay/Purity \\
\hline Nickel (II) nitrate hexahydrate for analysis & Merck (Darmstadt, Germany) & $99.0-102.0 \%$ \\
{$\left[\mathrm{Ni}\left(\mathrm{NO}_{3}\right)_{2} \cdot 6 \mathrm{H}_{2} \mathrm{O}\right]$} & PanReacAppliChem (Darmstadt, Germany) & $99.0 \%$ \\
Glycine for synthesis $\left[\mathrm{CH}_{2} \mathrm{NH}_{2} \mathrm{COOH}\right]$ & Riedel-de Haën (Bucharest, Romania) & $99.0 \%$ \\
Maleic acid [HOOCCH=CHCOOH] & Air liquide (Paris, France) & $99.999 \%$ \\
Hydrogen $\left[\mathrm{H}_{2}\right]$ &
\end{tabular}

The microstructural properties of the synthesized catalysts were determined by several methods. Atomic structure was determined by X-ray diffraction measurements in a Siemens Spellman DF3 spectrometer with $\mathrm{Cu}-\mathrm{K} \alpha$ radiation. For the semi-quantitative $\mathrm{XRD}$ analysis, $10 \% \mathrm{KCl}$ was added in all samples as an internal standard. By normalizing the XRD results against the $10 \% \mathrm{KCl}$ internal standard and calculating the peak ratio of intensities of particular peaks (ensuring that they were unique for each phase being analyzed), it was possible to determine the relative content of each phase in the material. The hkl of the peaks selected for each phase were: 111 for nickel, 101 for nickel oxide, and 100 for potassium chloride. 
Determination of the temperature and velocity of the combustion wave during SCS was carried out using three $100 \mu \mathrm{m}$ diameter K-type (chromel-alumel) thermocouples placed in and above the solution. A PICO TC-08 conditioner was used to convert, filter, and amplify the temperature signals, which were recorded at a rate of $0.5 \mathrm{~ms}$. The installation has been manufactured in the Advanced Ceramics \& Composite Materials Laboratory of NCSR “Demokritos" (Athens, Greece). No attempt was made to move the thermocouples since these measurements were used only to pinpoint the reaction time and correlate it to the appearance of the combustion phenomena. In any case, this work is being extended in order to compare the measured reaction temperatures with calculated adiabatic reaction temperatures, and will be published in future work. The temperature of the combustion wave was also measured in situ using a high-speed infrared (IR) camera (FLIR Systems, model A655SC, Wilsonville, Oregon, United States). The speed of the combustion wave was calculated by analysis of the data obtained from the high-speed infrared camera.

BET (Brunauer, Emmett and Teller) specific surface area and pore distribution measurements were carried out in a GAPP V-Sorb 2800 analyzer (Beijing, China) using nitrogen (99.9\%) with helium $(99.999 \%)$ as the carrier gas. All samples were subjected to degassing under vacuum $\left(3 \cdot 10^{-4}\right.$ Torr $)$ in two stages during pretreatment. During the first stage the samples were heated up to $80^{\circ} \mathrm{C}$ for $45 \mathrm{~min}$, while in the second stage they were heated up to $150{ }^{\circ} \mathrm{C}$ for another $45 \mathrm{~min}$.

The activity of the SCS catalysts was investigated in the aqueous hydrogenation of maleic acid that produced succinic acid, as presented in the equation below. The installation and its operating principles were extensively discussed in previous work [16].

$$
\mathrm{C}_{4} \mathrm{H}_{4} \mathrm{O}_{4}+\mathrm{H}_{2} \stackrel{\mathrm{Ni} / \mathrm{NiO}}{\rightarrow} \mathrm{C}_{4} \mathrm{H}_{6} \mathrm{O}_{4}
$$

The catalytic reaction took place in a shaker-reactor enclosed inside a water bath kept at $80^{\circ} \mathrm{C}$. An amount of $1.0 \mathrm{~g}$ of powdered catalyst was added into the catalytic reactor with $30 \mathrm{~mL}$ of distilled water. Thereafter, the $0.26 \mathrm{~g}$ maleic acid was added and calculated for the reaction with $50 \mathrm{~mL}$ of hydrogen at atmospheric pressure. Both catalyst saturation with hydrogen and hydrogenation were carried out under continuous horizontal shaking at a rate of about 500 cycles per minute. The amount of reacted hydrogen was measured every minute at atmospheric pressure. The installation has been manufactured in the Advanced Ceramics \& Composite Materials Laboratory of NCSR "Demokritos" (Athens, Greece).

To check reproducibility of the results, each experiment, analysis, and hydrogenation test was repeated at least three times.

\section{Results and Discussion}

An infrared camera was employed to take photographs of the samples with $75 \mathrm{~mL}$ of water in the precursor solution during combustion, and they are presented below in Figure 1. The photographs were taken at approximately the same time for the not-pretreated (a) and pretreated (b) samples at $70{ }^{\circ} \mathrm{C}$.

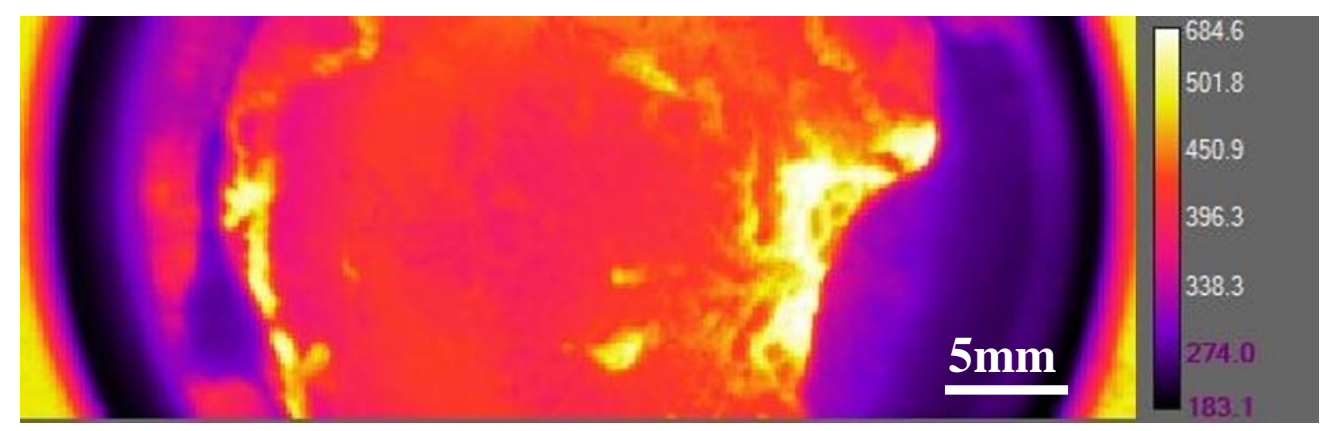

(a)

Figure 1. Cont. 


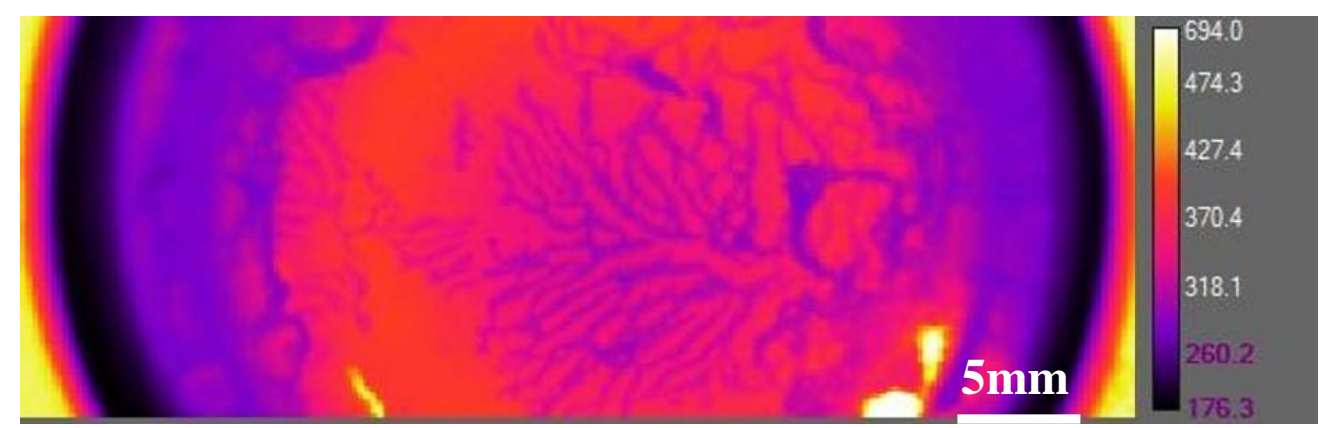

(b)

Figure 1. Photographs of the (a) not-pretreated and (b) pretreated samples during combustion, taken using an IR camera at $70^{\circ} \mathrm{C}$.

It can be observed from Figure 1 that there were well-developed and clearly distinguished dendrites when the pretreatment was applied on the precursor solution. On the other hand, in the not-pretreated sample there were no developed structures, indicating a different mechanism during SCS that resulted in a different composition and microstructure of the obtained nanopowders. The other three water quantities were also investigated, and the results were the same as those presented $(75 \mathrm{~mL}$ of water). At saturated nickel nitrate concentrations, dendrite growth in water can be explained from the perspective of a diffusion-limited aggregation process. The dendritic structure was due to the formation of hydrates while still in solution in combination with extensive gas emissions during SCS. These results were attributed to several controlling factors: the nickel nitrate crystal structure, the nature of diffusion through water as a solvent, the formation of nickel and nickel oxide, and the formation of strong bonds in glycine-nickel nitrate tetrahydrate $\left(\mathrm{C}_{2} \mathrm{H}_{13} \mathrm{~N}_{3} \mathrm{NiO}_{12}\right)$ during the reaction of glycine with nickel nitrate. It appeared that when these dendrites existed (with pretreatment) the reaction took place at a lower velocity as it was yielded through their complicated structure, and thus there was less time available for the oxidation of nickel.

In previous studies, there were several examples of dendrite formation during combustion synthesis. Vojisavljević et al. [19] studied the relationship between the combustion reaction mechanism induced by the exothermicity of the cobalt nitrate-glycine solution-combustion reactions and the morphological details of the nanocrystalline $\mathrm{Co}_{3} \mathrm{O}_{4}$ with a multi-branching tree-like form of the powders. They suggested that the high enthalpy of combustion, the rapid sintering, and formation of the grain boundaries typical for the strong bonding among cobalt-oxide nanocrystallites and short-string particles that occurred led to the formation of dendritic agglomerates [19].

Furthermore, the sol-gel combustion method was employed by Huang et al. [20] to synthesize modified salts based on the combustion of a sol or gel of $\mathrm{Mg}\left(\mathrm{NO}_{3}\right)_{2}$ and citric acid or urea in $\mathrm{NaNO}_{3}-\mathrm{KNO}_{3}$. These results showed that $\mathrm{MgO}$ nanoparticles possess a dendritic structure with a length of tens to hundreds of nanometers and notably by increasing fuel, the dendritic structure grew beyond the nanometer size [20].

Finally, $\mathrm{Ce}_{0.8} \mathrm{Sm}_{0.2} \mathrm{O}_{2-x}$ powders were derived by SCS using $\mathrm{Ce}\left(\mathrm{NO}_{3}\right)_{3} \cdot 6 \mathrm{H}_{2} \mathrm{O}$ and $\mathrm{Sm}\left(\mathrm{NO}_{3}\right)_{3} \cdot 6 \mathrm{H}_{2} \mathrm{O}$ as metal precursors and using different combustion fuel mixtures: (1) citric acid with ammonia, (2) cellulose and citric acid with a 2:1 molar ratio, and (3) sucrose. The reducer-oxidizer mixtures were stirred at $80{ }^{\circ} \mathrm{C}$ until a pale gel was formed. By further increasing the temperature, a white dendritic powder was formed for all combustion reactions [9].

Figure 2 demonstrates the patterns obtained from the XRD analysis for the examined nanopowders. 


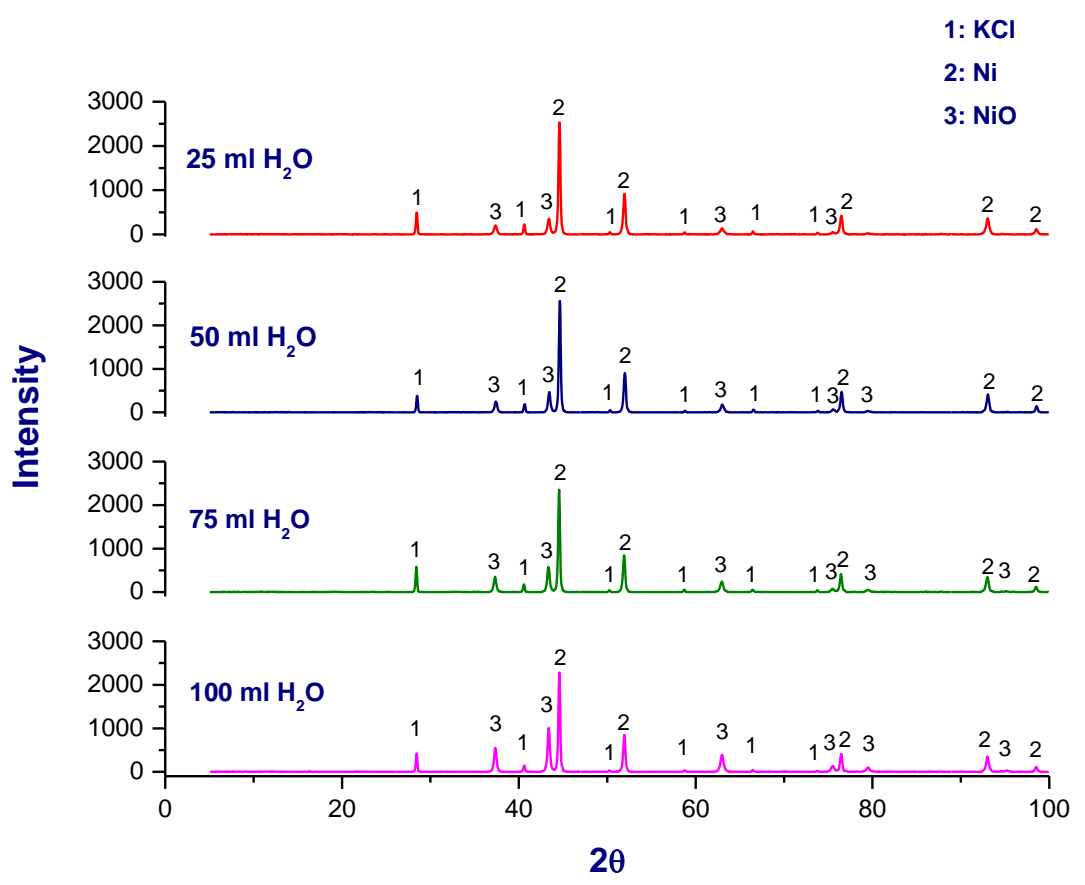

(a)
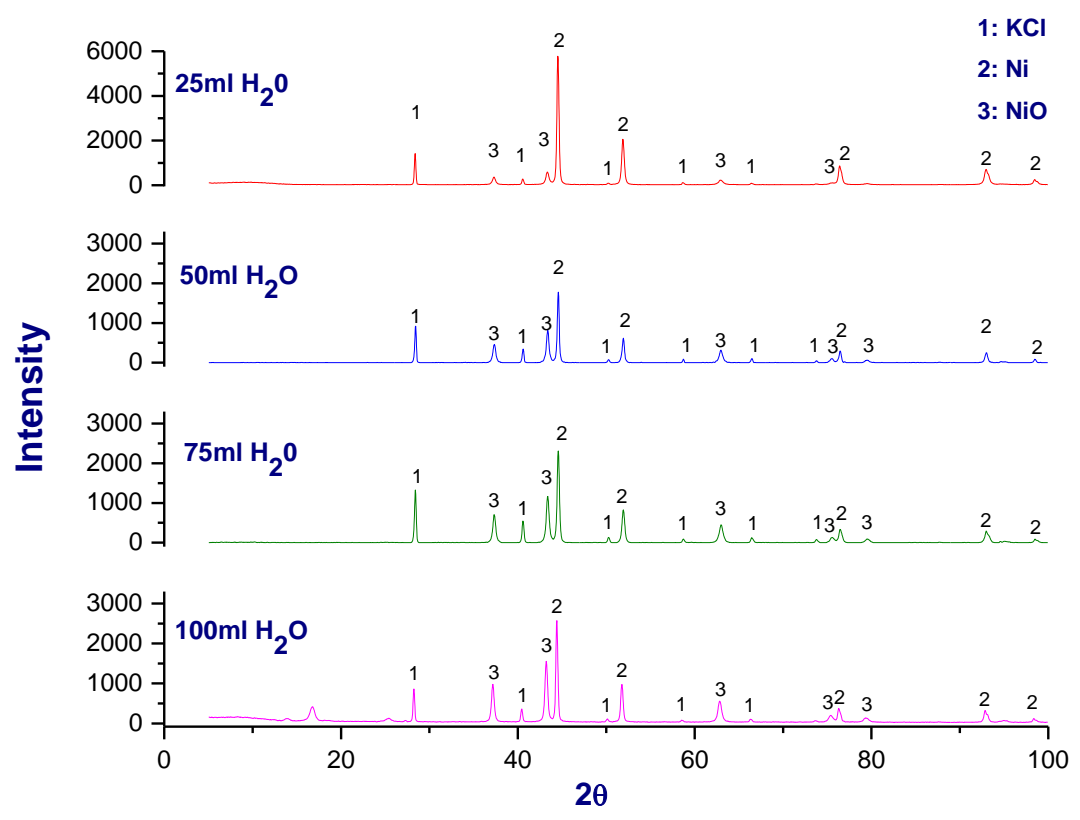

(b)

Figure 2. XRD patterns from the solution combustion synthesis (SCS) derived materials on the basis of the initial mixture of $66.7 \% \mathrm{Ni}\left(\mathrm{NO}_{3}\right)_{2} \cdot 6 \mathrm{H}_{2} \mathrm{O}$ and $33.3 \%$ glycine with different amounts of water added in the initial solution (a) with and (b) without heated stirring.

The XRD analysis revealed the major impact of the precursor solution's pretreatment. The two resulting phases, $\mathrm{Ni}$ and $\mathrm{NiO}$, appeared to exist in various ratios in the final product. Figure 3 presents the semi-quantitative analysis of these two phases as a function of the preparation conditions. 


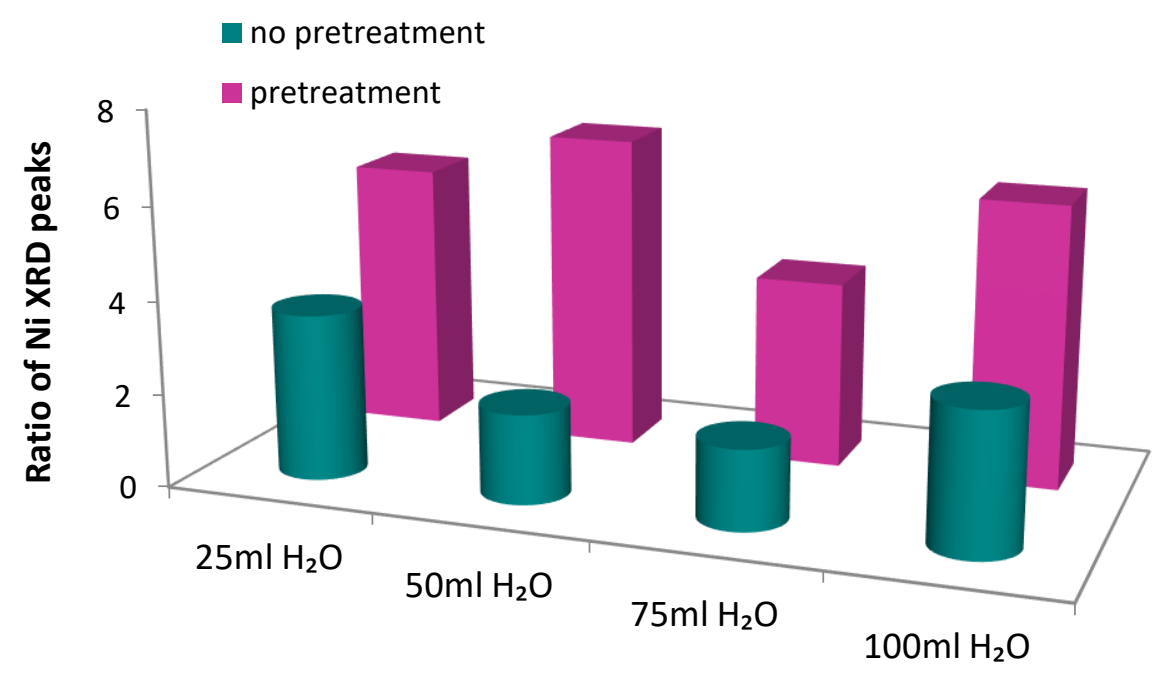

(a)

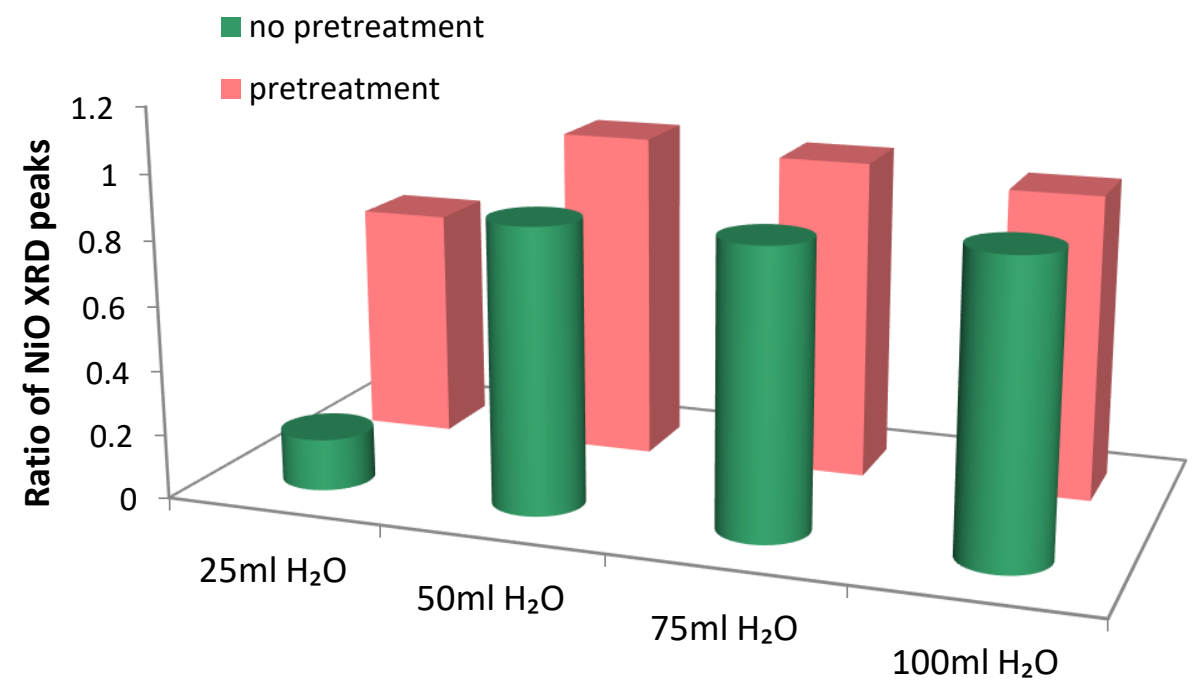

(b)

Figure 3. Semi-quantitative analysis of the (a) $\mathrm{Ni}$ and (b) $\mathrm{NiO}$ phases in the resulting materials.

Based on the data obtained by the XRD patterns, the heated stirring appeared to have a major influence on the final products' composition. When heated stirring was applied in the precursor SCS solution up to $70{ }^{\circ} \mathrm{C}$, the concentration of nickel in the final product was strongly enhanced, thus improving their catalytic activity in the liquid-phase hydrogenation of maleic acid. The pretreatment influenced the nickel nitrate-glycine complexes that were formed in the precursor solution in the form of dendrites, which play a key role in the SCS reaction mechanism and the formation of nickel. When these dendrites existed (with pretreatment) the reaction took place at lower velocity, as it was yielded through their complicated structure, and thus there was less time available for the oxidation of nickel. Furthermore, the heated stirring before SCS had a considerable effect on the nanopowders' microstructure as shown in Figures 4 and 5 that exhibit the calculated crystal lattice spacing and crystallite size for nickel and nickel oxide. The standard deviation for the crystal lattice spacing values was estimated to be $\pm 0.0005 \AA$ with a crystallite size of $\pm 3 \mathrm{~nm}$. 


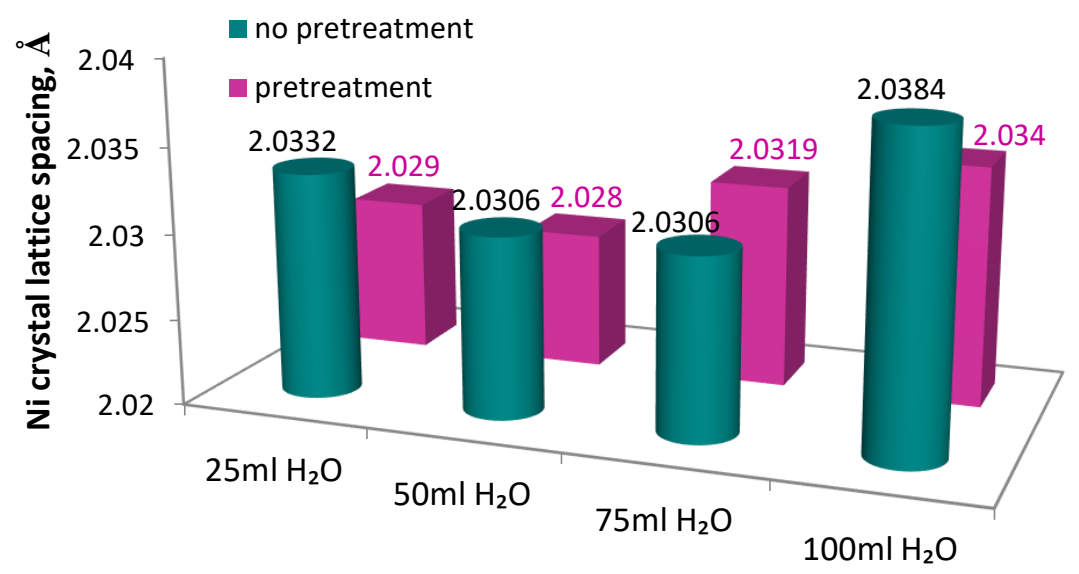

(a)

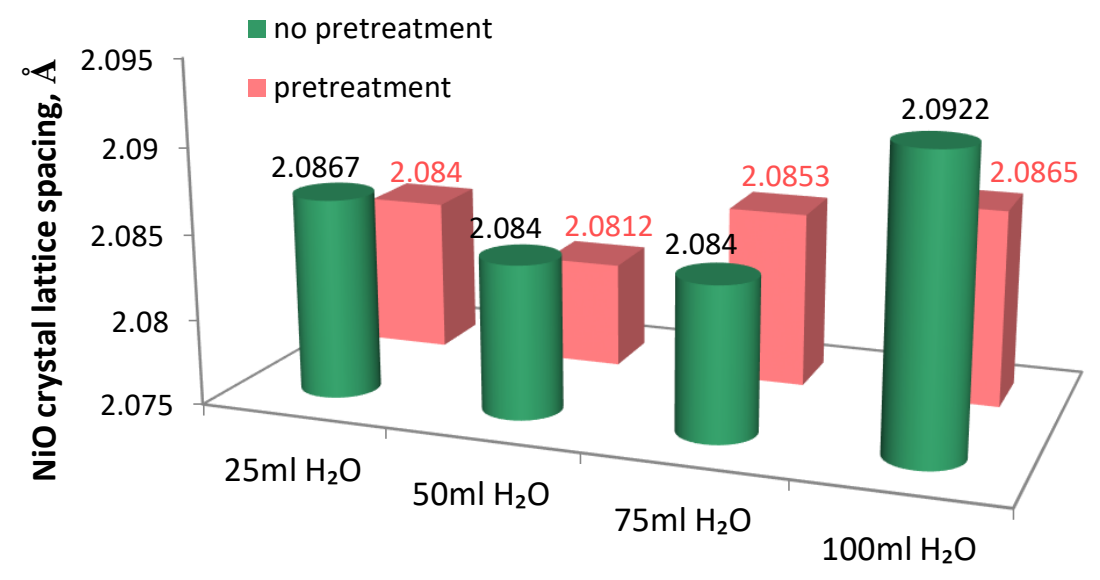

(b)

Figure 4. Influence of heated stirring on the crystal lattice spacing of (a) $\mathrm{Ni}$ and (b) $\mathrm{NiO}$.

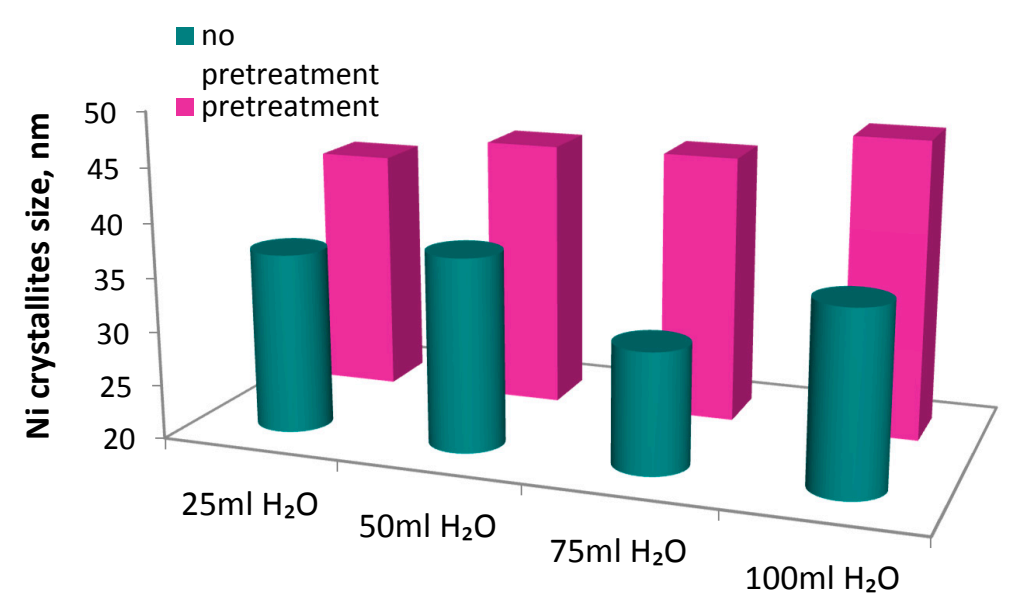

(a)

Figure 5. Cont. 


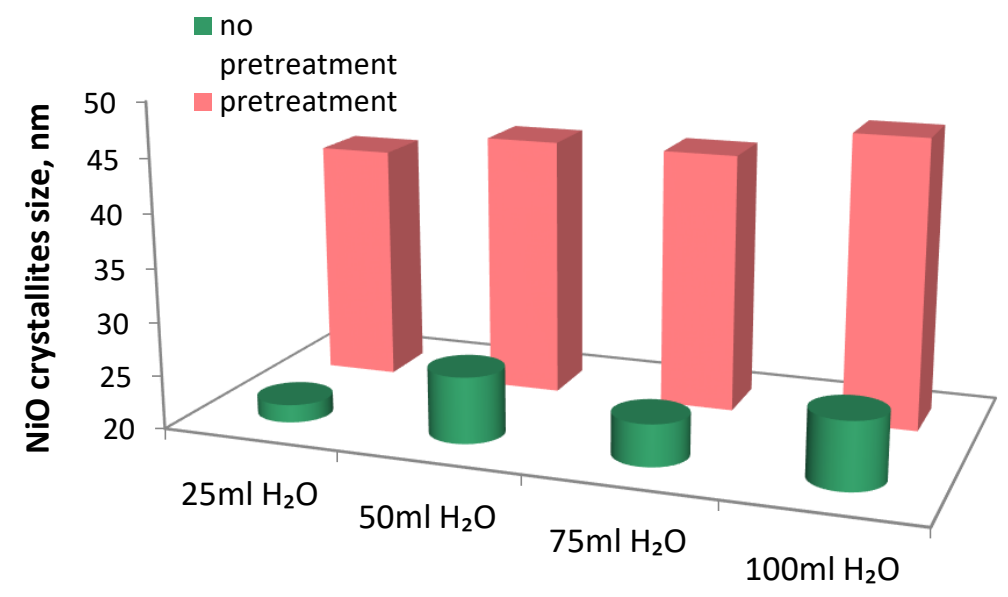

(b)

Figure 5. Influence of water quantity and heated stirring on the (a) $\mathrm{Ni}$ and (b) $\mathrm{NiO}$ crystallite size.

The pretreatment on the precursor solution appeared to have a more complicated influence on the crystal lattice spacing of nickel and nickel oxide. When 50 and $100 \mathrm{~mL}$ of water were added, pretreatment resulted in a reduction of crystal lattice spacing for both phases. On the other hand, when $75 \mathrm{~mL}$ of water was added in the initial mixture, the applied heated stirring did not significantly influence the crystal lattice spacing. The observed changes in the lattice spacing suggested alteration of the materials' defect structure, which is a major characteristic concerning their catalytic performance.

The influence of pretreatment on the crystallite size of nickel and nickel oxide was also clearly observed. The calculated (using Scherrer's formula) crystallite size of both phases grew when the pretreatment was applied on the initial SCS solution. The existence of dendrites led to the inhibition of oxygen diffusion on the foam-like structure due to the denser structure (i.e., lower height of dendrites in the final product). Accordingly, the oxidation of glycine was not completed, yielding carbon and carbon monoxide, which reduced nickel oxide to nickel. This double thermal treatment led to the occurrence of a sintering process and an increase of crystallite size. Larger crystallites have less surface energy and therefore tend to agglomerate less. The extent of crystallite agglomeration severely influenced the material's specific surface area, as shown in Figure 6. The standard deviation of the surface analyzer's values was estimated to be $\pm 0.1 \mathrm{~m}^{2} / \mathrm{g}$.

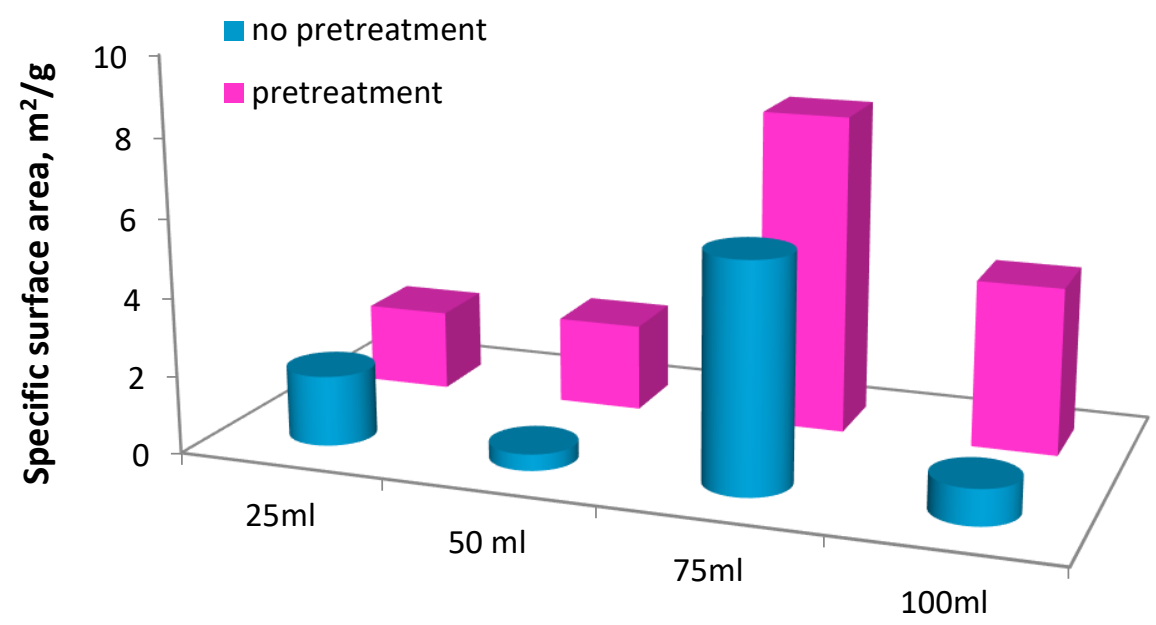

Figure 6. Influence of water quantity and heated stirring on the specific surface area of the produced materials. 
The specific surface area (SSA) of the as-burnt materials was also altered by the pretreatment of the precursor solution (refer to Figure 6). The effect of the pretreatment on the material's specific surface area was beneficial, as the SSA increased for both water quantities examined, suggesting its advantageous nature. These results are in accordance with the previous calculated crystallite size for pretreated and not-pretreated materials. The heated stirring resulted in larger crystallites for both phases, inhibiting the sintering process and leading to larger specific surface areas.

Adsorption-desorption curves obtained by the BET method are shown in Figure 7, where the hysteresis curves of the SCS products from a not-pretreated and a pretreated solution can be seen with $75 \mathrm{~mL}$ added into the initial mixture.

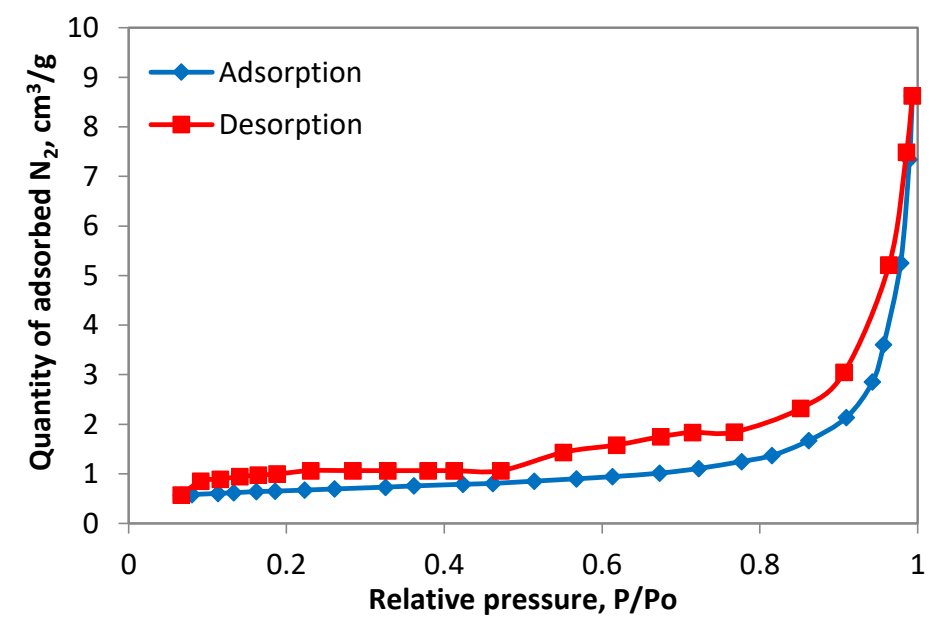

(a)

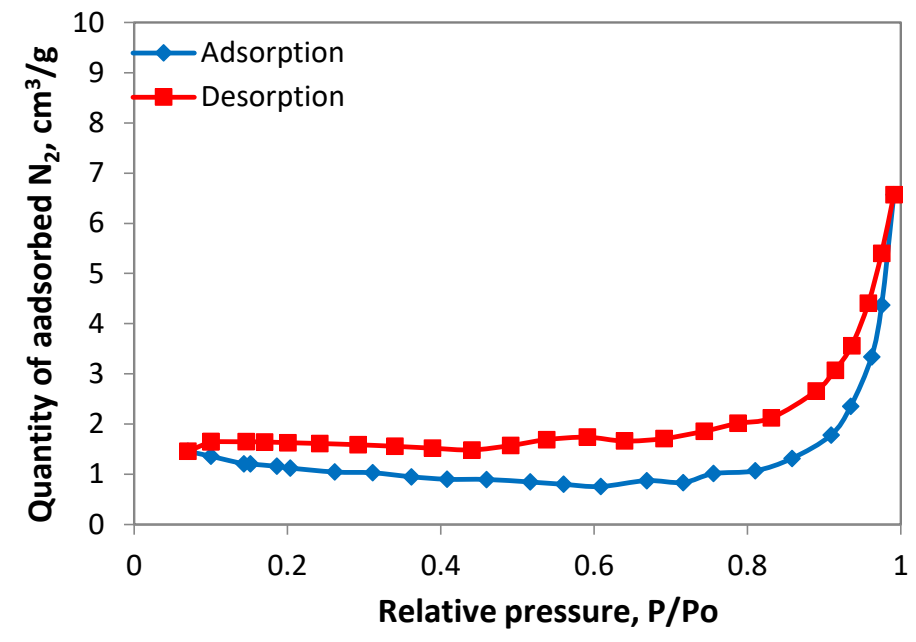

(b)

Figure 7. Hysteresis curves of the SCS materials prepared from (a) a not-pretreated and (b) a pretreated precursor solution.

The adsorption/desorption curves of the sample prepared without pretreatment of the initial SCS solution with $75 \mathrm{~mL}$ of added water are demonstrated in Figure $7 \mathrm{a}$, and the pretreated one in Figure $7 \mathrm{~b}$. Both materials exhibited a distinct hysteresis loop, indicating that evaporation from pores and condensation in the pores are two completely different processes. This in turn implies that capillary condensation occurs within mesopores. The shape of the hysteresis loop of the pretreated sample was type A, according to the De Boer categorization, suggesting the existence of mainly cylindrical pores. Moreover, the bigger loop indicates better pore connection, thus there were many open pores. On the other hand, the type of loop in the not-pretreated sample corresponded to type $C$ and its 
distinctly smaller hysteresis loop reflects the presence of many closed or semi-closed pores, such as wedge-shaped, cylindrical, and slit-shaped pores with one closed side or a dead end [21].

In addition, BET measurements provided the pore size distribution of the pretreated and not-pretreated samples in the case of $75 \mathrm{~mL}$ of water being added.

Pore analysis measurements are exhibited in Figure 8. The results showed that there was no significant effect of the pretreatment on the final product's volume of nanopores or total porosity. The porosity, as well as the volume of the nanopores, were mainly influenced by the volume and velocity of the generated gases, considering that the composition of the precursor solution was identical. Thus, the similar resulting porosity was due to the same initial composition and identical behavior of the generated gases, as the reaction that took place was the same. In conclusion, the different values of the specific surface area can be attributed to the various crystallite sizes of the resulting phases, and not the materials' porosity characteristics. Thermal measurements concerning the reaction temperature as a function of the reaction time are presented in Figure 9.

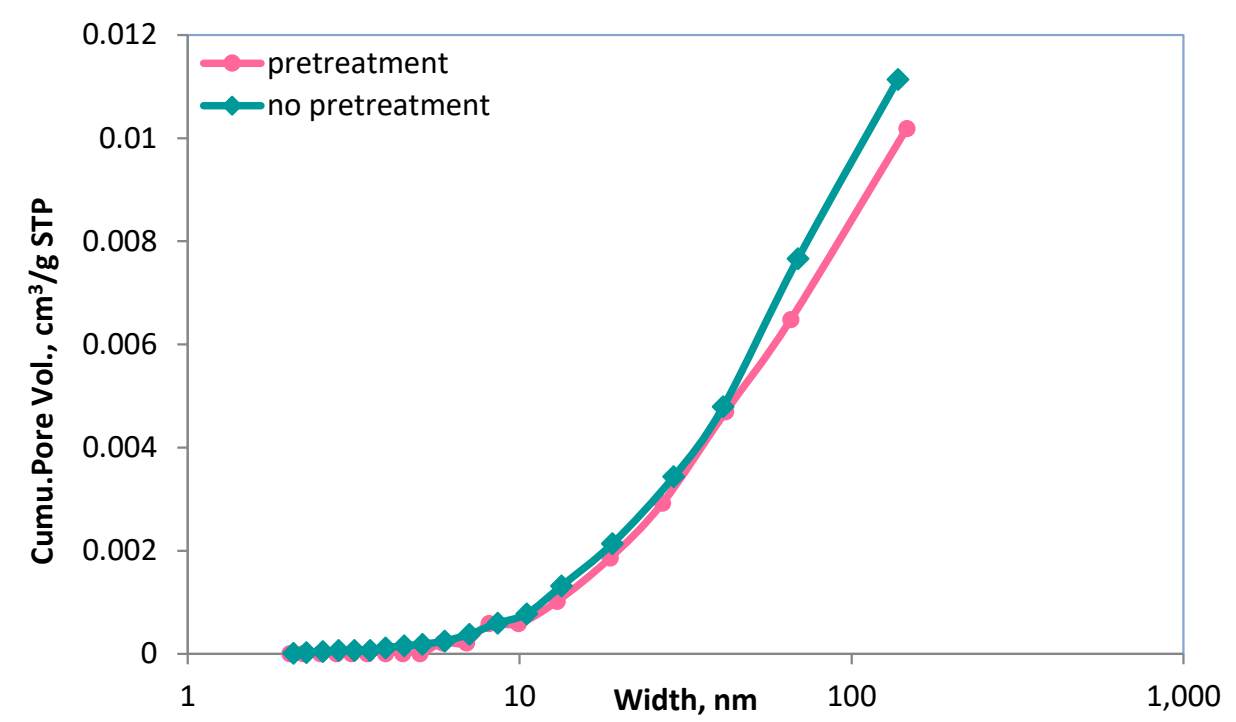

Figure 8. BJH (Barrett, Joyner, and Halenda) adsorption cumulative pore volume concerning the influence of pretreatment on the basis of the initial mixture of $66.7 \% \mathrm{Ni}\left(\mathrm{NO}_{3}\right)_{2}, 33.3 \%$ glycine, and $75 \mathrm{~mL} \mathrm{H}_{2} \mathrm{O}$.

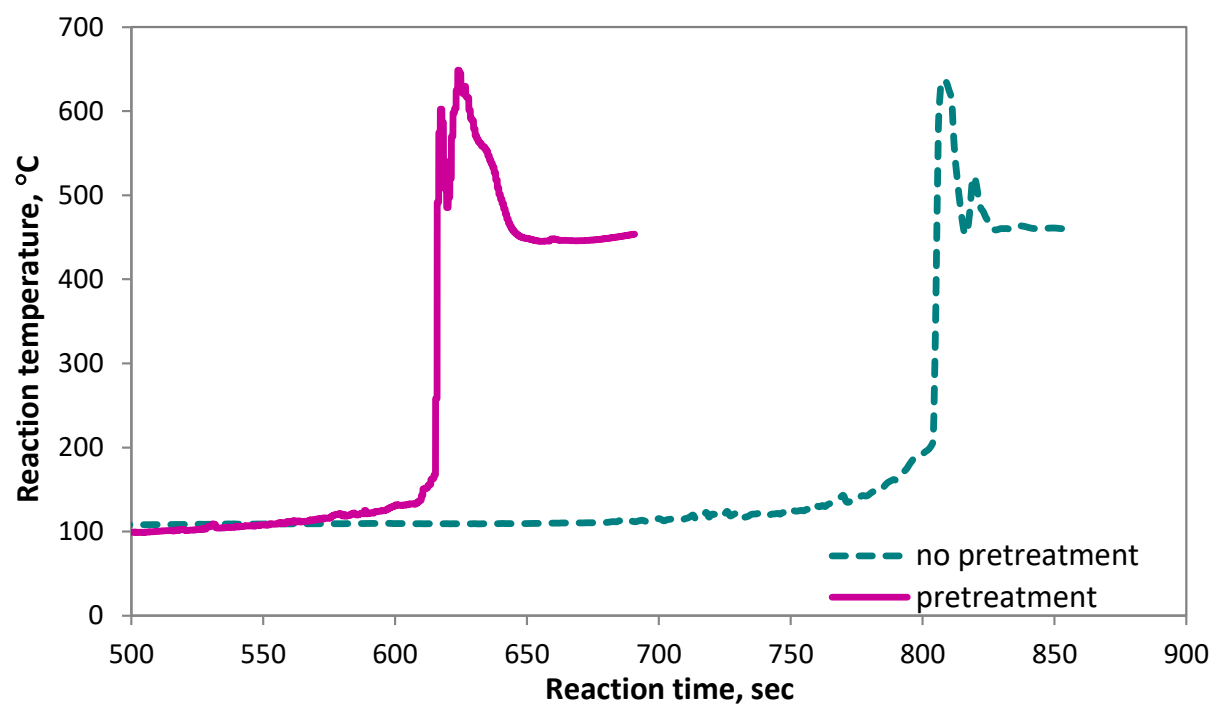

(a)

Figure 9. Cont. 


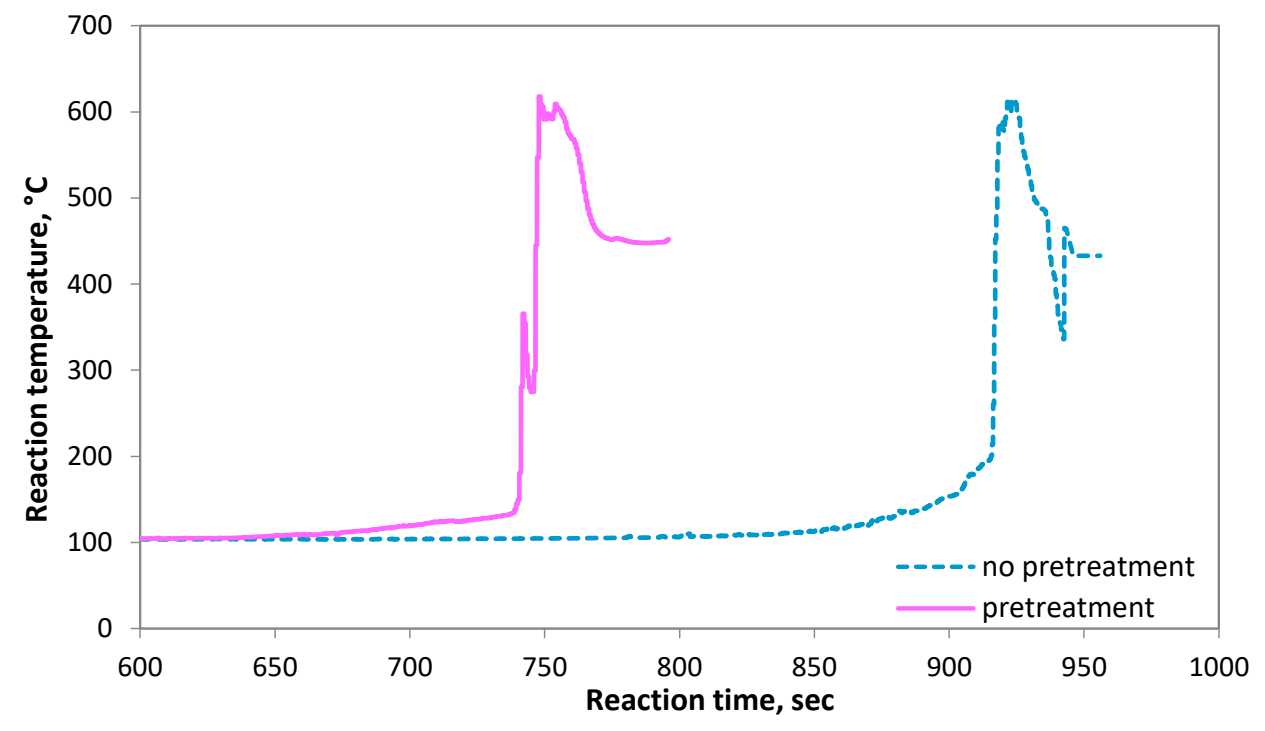

(b)

Figure 9. Reaction temperature as a function of reaction time during SCS for the samples with and without pretreatment on the basis of the initial mixture: (a) $66.7 \% \mathrm{Ni}\left(\mathrm{NO}_{3}\right)_{2}, 33.3 \%$ glycine, and $75 \mathrm{~mL}$ $\mathrm{H}_{2} \mathrm{O}$; and (b) $66.7 \% \mathrm{Ni}\left(\mathrm{NO}_{3}\right)_{2}, 33.3 \%$ glycine, and $100 \mathrm{~mL} \mathrm{H}_{2} \mathrm{O}$.

According to the obtained data, the pretreatment did not strongly influence the combustion temperature. The belated time of the combustion initiation for the not-pretreated sample was attributed to the quantity of the water that evaporated during the heated stirring. Nevertheless, the two observed peaks during SCS have different intensities and durations, implying a mechanism modification triggered only by the pretreatment application on the precursor solution. The first peak was attributed to the exothermic reaction of glycine with nickel nitrate, while the second to the reduction of nickel oxide with hydrogen and carbon. The resulting material of the pretreated solution had a more intensive and wider peak accorded to the nickel production, suggesting a higher concentration of nickel in the final product compared to the not-pretreated product. This was confirmed by the semi-quantitative analysis (refer to Figure 3), where the nickel concentration was indeed enhanced when pretreatment was applied.

The well-developed dendrites in the pretreated sample resulted in the alteration of the combustion mechanism in comparison with the not-pretreated one. When the pretreatment was applied, the reaction between glycine and nickel nitrate was slower, while in the second case it was more violent. The existence of dendrites led to the inhibition of oxygen diffusion on the foam-like structure due to the resulting more dense structure (i.e., lower height of dendrites in the final product). Correspondingly, the oxidation of glycine was not complete, yielding carbon and carbon monoxide, which reduced nickel oxide to nickel. That explains the higher second peak of the pretreated sample compared to the not-pretreated one, as well as the higher concentration of nickel in the final product composition.

The Ni-based synthesized materials were employed as catalysts. Their catalytic activity was tested in the liquid-phase hydrogenation of maleic acid, and conversion curves were obtained. The catalysts, which were prepared from pretreated precursor solutions, appeared to be more active, and the obtained conversion curves of the catalysts are shown in Figure 10. The standard deviation of the values of conversion was estimated to be $\pm 5 \%$.

The degree of the conversion of maleic acid into succinic acid was very low for the catalysts produced from a not-pretreated solution, whereas the catalysts made from pretreated solutions exhibited better catalytic activity, with the catalyst prepared with $75 \mathrm{~mL}$ of water showing the highest conversion rates. The enhanced catalytic performance of the catalysts prepared from the pretreated initial SCS solutions was due to their increased concentration of metallic nickel and their increased surface area (due to increasing crystallite size and decreasing sintering processes). Nickel acts as a 
catalyst in the hydrogenation of maleic acid, and the increase of nickel concentration led to an increase of the catalysts' activity. Increasing surface area resulted in the enhancement of the catalysts' activity, as liquid-phase hydrogenation was characterized as a surface catalysis, where the reactant molecules were adsorbed onto a solid surface before they reacted with the catalyst to form the product. The rate of the surface-catalyzed reaction increased with the increase of the catalyst surface area in contact with the reactants.

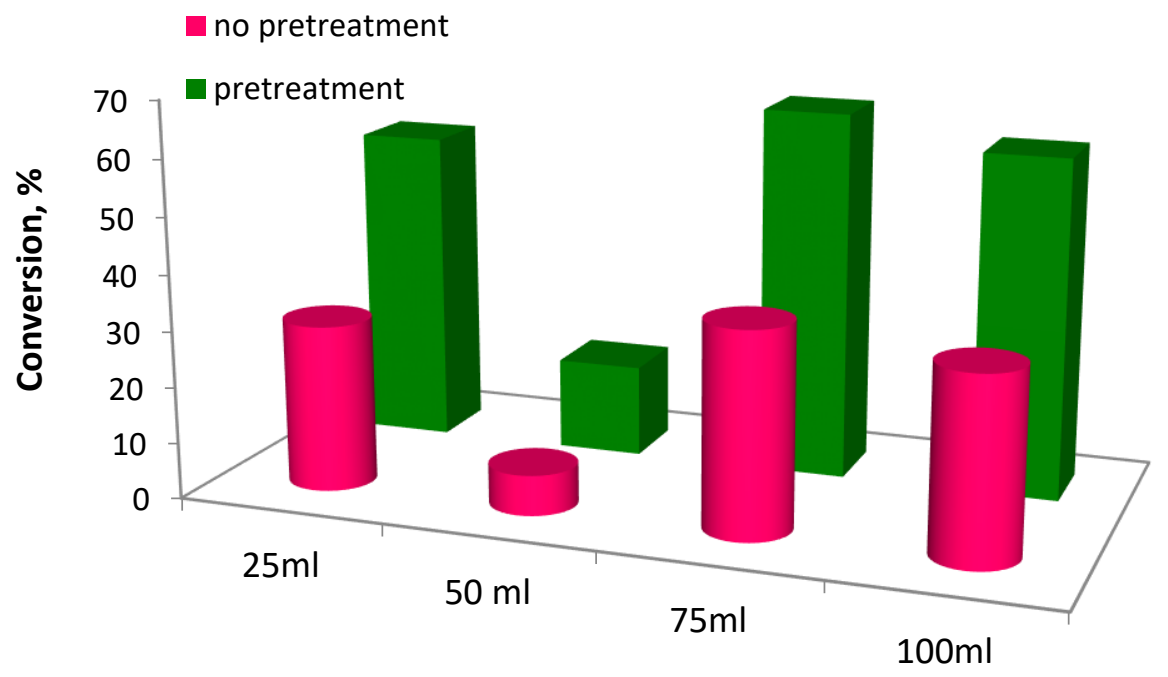

Figure 10. The dependence of maleic acid conversion on the SCS catalysts, calculated from the quantity of absorbed hydrogen.

Improved specific surface area, the open porosity for the catalyst with $75 \mathrm{~mL}$ of water as suggested by the obtained adsorption/desorption curves, as well as the optimum crystal lattice plane size for adsorption-desorption process of reaction components played a significant role in improving its catalytic activity compared to the other amounts of water that were added in the initial mixture.

\section{Conclusions}

The main findings of the present study are:

1. The pretreatment influenced the nickel nitrate-glycine complexes that were formed in the precursor solution in the form of dendrites, which played a key role in the SCS reaction mechanism and the formation of nickel.

2. The existence of dendrites led to the inhibition of oxygen diffusion on the foam-like structure due to the resulting denser structure (i.e., lower height of dendrites in the final product).

3. In accordance, the oxidation of glycine was not complete, yielding carbon and carbon monoxide, which reduced nickel oxide to nickel. This "double thermal treatment" led to the occurrence of a sintering process and an increase of crystallite size.

4. Larger crystallites had less surface energy and as a result they tended to agglomerate less, leading to enhanced specific surface area.

These results help to explain phenomena which have been observed during SCS, such as dendrite formation. The influence of pretreatment may explain many of the difficulties reported in repeating synthesis, since this parameter generally was not taken into consideration during the investigation of nanomaterials synthesis.

Thus, the consideration of pretreatment's influence has significant potential applications in the preparation of other nanocomposite catalysts for engineering highly efficient catalysts and also for researchers that are occupied with nanomaterials. 
Author Contributions: Conceptualization, G.X. and O.T.; methodology, O.T.; software, O.T.; validation, G.X. and G.V.; formal analysis, O.T.; investigation, O.T. and G.X.; data curation, G.X.; writing-original draft preparation, O.T.; writing—review and editing, O.T. and G.X.; visualization, O.T. and G.X.; supervision, G.X. and A.C.

Funding: This research received no external funding.

Acknowledgments: The authors would like to thank Sergey Roslyakov (National University of Science and Technology "MISIS", Moscow, Russia) for the captions during SCS with the IR-high speed camera.

Conflicts of Interest: The authors declare no conflict of interest.

\section{References}

1. Deganello, F.; Tyagi, A.K. Solution combustion synthesis, energy and environment: Best parameters for better materials. Prog. Cryst. Growth Charact. Mater. 2018, 64, 23-61. [CrossRef]

2. Varma, A.; Mukasyan, A.S.; Rogachev, A.S.; Manukyan, K.V. Solution combustion synthesis of nanoscale materials. Chem. Rev. 2016, 116, 14493-14586. [CrossRef] [PubMed]

3. Mukasyan, A.S.; Rogachev, A.S. Thermal Explosion Mode of Combustion Synthesis. In Concise Encyclopedia of Self-Propagating High-Temperature Synthesis, History, Theory, Technology, and Products, 1st ed.; Borovinskaya, I., Gromov, A., Levashov, E., Maksimov, Y., Mukasyan, A., Rogachev, A., Eds.; Elsevier: Amsterdam, The Netherlands, 2017; pp. 379-381.

4. Hong, S.-A.; Nam, S.W. Application of sol-gel techniques in fabrication of fuel cells. Stud. Surf. Sci. Catal. 2006, 159, 79-84.

5. Villa, P.L.; Lietti, L. Effect of the preparation procedure and parameters on the physico-chemical properties of higher alcohol synthesis ZnCrO catalysts. Stud. Surf. Sci. Catal. 1998, 118, 395-402.

6. Köferstein, R.; Walther, T.; Hesse, D.; Ebbinghaus, S.G. Fine-grained $\mathrm{BaTiO}_{3}-\mathrm{MgFe}_{2} \mathrm{O}_{4}$ composites prepared by a Pechini-like process. J. Alloys Compd. 2015, 638, 141-147.

7. Zhang, H.; Yang, D.; Ji, Y.; Ma, X.; Xu, J.; Que, D. Low Temperature Synthesis of Flowerlike ZnO Nanostructures by Cetyltrimethylammonium Bromide-Assisted Hydrothermal Process. J. Phys. Chem. B 2004, 108, 3955-3958. [CrossRef]

8. Mukasyan, A.S.; Dinka, P. Novel approaches to solution-combustion synthesis of nanomaterials. Int. J. Self-Propag. High-Temp. Synth. 2007, 16, 23-35. [CrossRef]

9. Aliotta, C.; Liotta, L.F.; La Parola, V.; Martorana, A.; Muccillo, E.N.S.; Muccillo, R.; Deganello, F. Ceria-based electrolytes prepared by solution combustion synthesis: The role of fuel on the materials properties. Appl. Catal. B 2016, 197, 14-22. [CrossRef]

10. González-Cortés, S.L.; Imbert, F.E. Fundamentals, properties and applications of solid catalysts prepared by solution combustion synthesis (SCS). Appl. Catal. A 2013, 452, 117-131. [CrossRef]

11. Li, F.; Ran, J.; Jaroniec, M.; Qiao, S.Z. Solution combustion synthesis of metal oxide nanomaterials for energy storage and conversion. Nanoscale 2015, 7, 17590-17610. [CrossRef] [PubMed]

12. Thoda, O.; Xanthopoulou, G.; Vekinis, G.; Chroneos, A. Review of Recent Studies on Solution Combustion Synthesis of Nanostructured Catalysts. Adv. Eng. Mater. 2018, 20. [CrossRef]

13. Wen, W.; Wu, J.-M. Nanomaterials via solution combustion synthesis: A step nearer to controllability. RSC Adv. 2014, 4, 58090-58100. [CrossRef]

14. Kim, M.-G.; Kanatzidis, M.G.; Facchetti, A.; Marks, T.J. Low-temperature fabrication of high-performance metal oxide thin-film electronics via combustion processing. Nat. Mater. 2011, 10, 382-388. [CrossRef] [PubMed]

15. Thoda, O.; Xanthopoulou, G.; Prokof'ev, V.; Roslyakov, S.; Vekinis, G.; Chroneos, A. Influence of Preheating Temperature on Solution Combustion Synthesis of Ni-NiO Nanocomposites: Mathematical Model and Experiment. Int. J. Self-Propag. High-Temp. Synth. 2018, 27, 207-215. [CrossRef]

16. Thoda, O.; Xanthopoulou, G.; Vekinis, G.; Chroneos, A. Parametric optimisation of solution combustion synthesis catalysts and their application for the aqueous hydrogenation of maleic acid. Catal. Lett. 2018, 148, 764-778. [CrossRef]

17. Xanthopoulou, G.; Thoda, O.; Roslyakov, S.; Steinman, A.; Kovalev, D.; Levashov, E.; Vekinis, G.; Sytschev, A.; Chroneos, A. Solution combustion synthesis of nano-catalysts with a hierarchical structure. J. Catal. 2018, 364, 112-124. [CrossRef] 
18. Xanthopoulou, G.; Thoda, O.; Metaxa, E.D.; Vekinis, G.; Chroneos, A. Influence of atomic structure on the nano-nickel-based catalyst activity produced by solution combustion synthesis in the hydrogenation of maleic acid. J. Catal. 2017, 348, 9-21. [CrossRef]

19. Vojisavljević, K.; Wicker, S.; Can, I.; Benčan, A.; Barsan, N.; Malič, B. Nanocrystalline cobalt-oxide powders by solution-combustion synthesis and their application in chemical sensors. Adv. Powder Technol. 2017, 28, 1118-1128.

20. Huang, Y.; Cheng, X.; Li, Y.; Shi, D.; Li, G.; Xu, K. Effect of sol-gel combustion synthesis of nanoparticles on thermal properties of $\mathrm{KNO}_{3}-\mathrm{NaNO}_{3}$. Sol. Energy Mater. Sol. Cells 2018, 188, 190-201. [CrossRef]

21. Nie, B.; Liu, X.; Yang, L.; Meng, J.; Li, X. Pore structure characterization of different rank coals using gas adsorption and scanning electron microscopy. Fuel 2015, 158, 908-917. [CrossRef]

2019 by the authors. Licensee MDPI, Basel, Switzerland. This article is an open access article distributed under the terms and conditions of the Creative Commons Attribution (CC BY) license (http:/ / creativecommons.org/licenses/by/4.0/). 